\title{
Alex OWEN, The Place of Enchantment. British Occultism and the Culture of the Modern
}

Chicago - London, University of Chicago Press, 2004, 355 p.

\section{Françoise Champion}

\section{CpenEdition}

Journals

Édition électronique

URL : http://journals.openedition.org/assr/21175

DOI : $10.4000 /$ assr.21175

ISSN : 1777-5825

Éditeur

Éditions de l'EHESS

Édition imprimée

Date de publication : 31 décembre 2009

Pagination : $75-342$

ISBN : 978-2-7132-2218-4

ISSN : 0335-5985

Référence électronique

Françoise Champion, «Alex owEN, The Place of Enchantment. British Occultism and the Culture of the Modern », Archives de sciences sociales des religions [En ligne], 148 | octobre-décembre 2009, document 148-98, mis en ligne le 03 juin 2009, consulté le 21 septembre 2020. URL : http:// journals.openedition.org/assr/21175; DOI : https://doi.org/10.4000/assr.21175

Ce document a été généré automatiquement le 21 septembre 2020.

(C) Archives de sciences sociales des religions 


\section{Alex OWEN, The Place of Enchantment. British Occultism and the Culture of the Modern}

Chicago - London, University of Chicago Press, 2004, 355 p.

Françoise Champion

\section{RÉFÉRENCE}

Alex owEN, The Place of Enchantment. British Occultism and the Culture of the Modern, Chicago - London, University of Chicago Press, 2004, 355 p.

1 Si le titre de l'ouvrage, British Occultism and the Culture of the Modern laisse planer quelque doute sur le lien entre l'occultisme qu'étudie l'auteur (celui des années 1880-1914) et la culture moderne, l'incertitude est très vite levée: les mouvements " occultes » et «magiques » qui se développent entre les années 1880 et le début de la Grande Guerre appartiennent pleinement à la modernité « fin de siècle » (en français dans le texte puisque l'expression française a été adoptée par les diverses langues européennes). Cette « fin de siècle » connaît un large "renouveau mystique », chrétien pour une part - et notamment catholique -, mais le mouvement dominant, estime l'auteur, s'écarte du christianisme pour prendre des voies hétérodoxes qui constituent une manière de traverse pour articuler spiritualité et rationalité moderne.

2 L'auteur se focalise principalement sur l'Ordre hermétique de l'Aube dorée, the Hermetic Order of the Golden Dawn, mais également sur la nouvelle impulsion qu'A. Besant donne alors à la Société théosophique - deux groupes qui ont eu un développement international - ainsi que sur d'autres groupes moins importants appréhendés à travers leurs revues.

3 Ce mouvement occulte fin de siècle est différent du mouvement spirite, pluriel, des décades précédentes qui constituait essentiellement une revitalisation et une démocratisation, certes hétérodoxe, du christianisme. Il revitalise la tradition 
ésotérique judéo-chrétienne, notamment rosicrucienne, cultivant le secret et les hiérarchies, mettant l'accent sur l'étude et non pas sur de "vulgaires » charismes. Ces caractéristiques en font un mouvement concernant les élites éduquées. Ainsi appartenaient au Golden Dawn l'écrivain W.B. Yeats, la patriote irlandaise Maud Gonne, l'actrice et féministe Florence Farr, Mina Bergson (la sœur d'Henri Bergson, mariée au puissant chef du Golden Dawn et qui avait pris le prénom celte de Moina et le nom de son mari, MacGregor Mathers). Ces personnalités et bien d'autres plus ou moins intensément engagées dans les mouvements occultes de l'époque ont des liens avec toutes les avant gardes esthétiques et socialisantes (le mouvement fabien en particulier) de l'époque, par exemple à travers le magazine littéraire d'influence New Age édité par A.R. Orage qui cherchait à articuler socialisme, théosophie et nietzschéisme - dans ce magazine le poète Edwin Muir tenait une chronique "nous modernes». Ce «nous modernes» a alors une forte signification: un optimisme marqué d'anxiété, celle liée à la crainte du déclin de l'empire, d'un déclin culturel, d'un effondrement des sociétés modernes, déclins qui se traduiront dans le déclenchement de la première guerre mondiale.

4 L'auteur développe son propos en huit chapitres en commençant par une mise en perspective générale de la culture et de l'occultisme fin de siècle. Parmi les principaux points abordés dans les chapitres suivants : les divers exploits magiques des nouveaux occultistes (et tout particulièrement leurs voyages astraux), leur " politique sexuelle ", les alliances entre science et philosophie occulte qu'ils opèrent tentant ainsi d'inventer une nouvelle rationalité. Un chapitre entier est consacré à Crossley. De ce personnage très singulier Alex Owen retient au final son incessante interrogation de la subjectivité par des méthodes magiques. En fait cette question de la subjectivité est celle qui retient centralement son attention. Elle conçoit moins l'invention de l'occultisme fin de siècle, en replaçant celle-ci dans le champ religieux, comme alternative à la religion traditionnelle affrontée à la montée de la raison moderne, que comme une des nouvelles manières de comprendre l'esprit qui s'inventent alors. Ces nouvelles manières cherchent toutes à explorer, non pas le sujet de la raison, mais l'intériorité personnelle, le self («le moi » est en français la traduction la moins mauvaise), en particulier dans ses dimensions d'irrationalité, que celle-ci soit nommée inconscient, imagination, intuition, élan vital... A. Owen s'intéresse aux liens marqués d'intérêt et de distance qu'ont ainsi pu entretenir avec le mouvement occultiste Freud, Janet, Jung, Bergson, James, etc.

5 L'ouvrage constitue une contribution intéressante aux analyses qui, impulsées sans doute par le mouvement de réactivation «mystique-ésotérique » des années soixantedix, manifestement moderne, a conduit à revisiter d'anciens groupes ésotériques pour y voir combien ils sont loin d'avoir principalement alimenté un traditionalisme et une réaction politique comme on y avait longtemps insisté (néanmoins A. Owen observe aussi des éléments en ce sens, par exemple lorsqu'il s'agit de la Régénération de la Race humaine). Le travail de A. Owen s'inscrit donc dans une lignée de recherche et ne constitue pas, comme il y insiste, une rupture absolument novatrice avec des recherches qui auraient, elles, creusé le seul sillon du désenchantement wébérien. Comme d'autres travaux il analyse précisément les transactions, les "renégociations ", nous dit A. Owen, entre tradition et modernité, entre enchantement et désenchantement. Il permet aussi une comparaison avec le renouveau mystiqueésotérique des années soixante-dix à quatre-vingt-dix. Celui-ci refuse le secret, l'élitisme, l'intellectualisme cultivé par l'occultisme fin de siècle. En revanche il y a une 
proximité dans l'ambivalence des deux renouveaux à l'égard de la modernité et du progrès. Dans les deux mouvements celui-ci est d'abord progrès de soi ; mais pour le renouveau des années soixante-dix comme pour toutes les spiritualités progressives d'aujourd'hui, la centralité de l'intériorité proprement psychologique est un acquis décisif.

6 L'ouvrage se lit d'abord avec grand plaisir car le style est agréable et l'argument vigoureux. Mais, progressivement, la répétition de celui-ci - la modernité de l'occultisme fin de siècle - sans avancées majeures dans le terrain et les analyses, finissent par lasser; d'autant plus que l'absence d'intertitres au sein des chapitres (de trente à quarante pages) ne permet pas de structurer la lecture. 